\title{
Carbon ion radiotherapy as definitive treatment in locally recurrent pancreatic cancer
}

\author{
Jakob Liermann ${ }^{1,2,5}$ (D) Edgar Ben-Josef . Mustafa Syed $^{1,2,5}$. Juergen Debus ${ }^{1,2,3,4,5,7} \cdot$ Klaus Herfarth $^{1,2,3,4,5,7}$. \\ Patrick Naumann ${ }^{1,2,5}$
}

Received: 30 December 2020 / Accepted: 5 July 2021 / Published online: 5 August 2021

(c) The Author(s) 2021

\begin{abstract}
Purpose Data on management of locally recurrent pancreatic cancer (LRPC) after primary resection are limited. Recently, surprisingly high overall survival rates were reported after irradiation with carbon ions. Here, we report on our clinical experience using carbon ion radiotherapy as definitive treatment in LRPC at the Heidelberg Ion-Beam Therapy Center (HIT).

Methods Between 2015 and 2019, we treated 13 patients with LRPC with carbon ions with a median total dose of 48 Gy (RBE) in 12 fractions using an active raster-scanning technique at a rotating gantry. No concomitant chemotherapy was administered. Overall survival, local control, and toxicity rates were evaluated 18 months after the last patient finished radiotherapy.

Results With a median follow-up time of 9.5 months, one patient is still alive (8\%). Median OS was 12.7 months. Ten patients $(77 \%)$ developed distant metastases. Additionally, one local recurrence (8\%) and two regional tumor recurrences (15\%) were observed. The estimated 1-year local control and locoregional control rates were $87.5 \%$ and $75 \%$, respectively. During radiotherapy, we registered one gastrointestinal bleeding CTCAE grade III (8\%) due to gastritis. The bleeding was sufficiently managed with conservative therapy. No further higher-grade acute or late toxicities were observed.

Conclusion We demonstrate high local control rates in a rare cohort of LRPC patients treated with carbon ion radiotherapy. The observed median overall survival rate was not improved compared to historical in-house data using photon radiotherapy. This is likely due to a high rate of distant tumor progression, highlighting the necessity of additional chemotherapy.
\end{abstract}

Keywords Pancreatic cancer $\cdot$ Carbon ion radiotherapy $\cdot$ Particle therapy $\cdot$ Locally recurrent pancreatic cancer $\cdot$ Radiation oncology

\section{Background}

Pancreatic cancer is one of the most aggressive tumors, with a 5-year overall survival (OS) rate of 5-10\% [1]. The only curative treatment option is primary resection. Resection should always be performed if possible [2]. But even

Dr. Jakob Liermann, MD

Jakob.Liermann@med.uni-heidelberg.de

1 Department of Radiation Oncology, Heidelberg University Hospital, Im Neuenheimer Feld 400, 69120 Heidelberg, Germany

2 Heidelberg Institute of Radiation Oncology (HIRO), Im Neuenheimer Feld 400, 69120 Heidelberg, Germany

3 National Center for Tumor Diseases (NCT), Im Neuenheimer Feld 460, 69120 Heidelberg, Germany after surgery, approximately $80 \%$ of the patients die within 5 years $[3,4]$. About a quarter of operated patients develop local tumor recurrence [5]. If the tumor burden remains restricted to the pancreas or to the operation bed, local treatment options should be considered. This is significant, as approximately $30 \%$ of all pancreatic cancer-related deaths
4 Clinical Cooperation Unit Radiation Oncology, German Cancer Research Center (DKFZ), Im Neuenheimer Feld 280, 69120 Heidelberg, Germany

5 Heidelberg Ion-Beam Therapy Center (HIT), Im Neuenheimer Feld 450, 69120 Heidelberg, Germany

6 Department of Radiation Oncology, University of Pennsylvania, Philadelphia, USA

7 German Cancer Consortium (DKTK), partner site Heidelberg, German Cancer Research Center (DKFZ), Im Neuenheimer Feld 280, 69120 Heidelberg, Germany 
are due to local tumor burden [6]. Data on management of locally recurrent pancreatic cancer (LRPC) are scarce. Reresection is considered the best treatment option, as several reports demonstrated a postoperative median OS of 25-26 months [7, 8] and a pooled analysis showed a 5year OS rate of $40.6 \%$ [9]. Conventional fractionated photon radiotherapy in LRPC has been investigated in several retrospective reviews, but efficacy remains poor [10, 11]. However, in inoperable cases, radiotherapy or chemoradiotherapy should be discussed.

Modern radiation techniques such as stereotactic body radiotherapy (SBRT) or particle therapy are characterized by a steeper dose gradient. This gradient results in an improved sparing of organs at risk (OARs), allowing delivery of a higher biological effective dose (BED) to the gross tumor volume (GTV). The efficacy of SBRT in LRPC was analyzed by Comito et al., who observed a median OS of 18 months after irradiating with $45 \mathrm{~Gy}$ in 6 fractions [12]. In 2018, Ryan et al. reported on 51 patients treated with SBRT with a total dose of 25-33 Gy in 5 fractions, mostly (59\%) followed by maintenance chemotherapy [13]. The median OS was 16 months, although the study included patients receiving re-irradiation. For response evaluation of radiotherapy, highly precise imaging techniques should be used [14].

Particle therapy could be more effective than SBRT in the management of LRPC due to its biological and/or physical advantages over photon radiotherapy [15]. Mizumoto et al. observed a median OS of 26.1 months after radiotherapy with protons with a total dose of $67.5 \mathrm{~Gy}$ (RBE) in 19-25 fractions, mostly (83\%) combined with chemotherapy [16]. Gastrointestinal bleeding was frequent (43.3\%). One patient $(3.3 \%)$ developed grade III bleeding. Another three patients (10\%) developed grade III spinal fractures.

The only data available on the efficacy of carbon ion radiotherapy in LRPC were published in 2018. In this retrospective analysis, Kawashiro et al. demonstrated a median OS of 25.9 months after carbon ion radiotherapy with a total dose of 52.8-55.2 Gy (RBE) in 12 fractions, predominantly (57\%) combined with chemotherapy [17]. Radiotherapy with carbon ions seemed safe, without any highgrade radiation-induced toxicity. These promising data explain the growing interest in the efficacy of particle therapy in pancreatic cancer, but no additional supporting results have been published.

In the present study, we analyzed the feasibility, safety, and efficacy of irradiation with carbon ions in LRPC patients at the Heidelberg Ion-Beam Therapy Center (HIT).

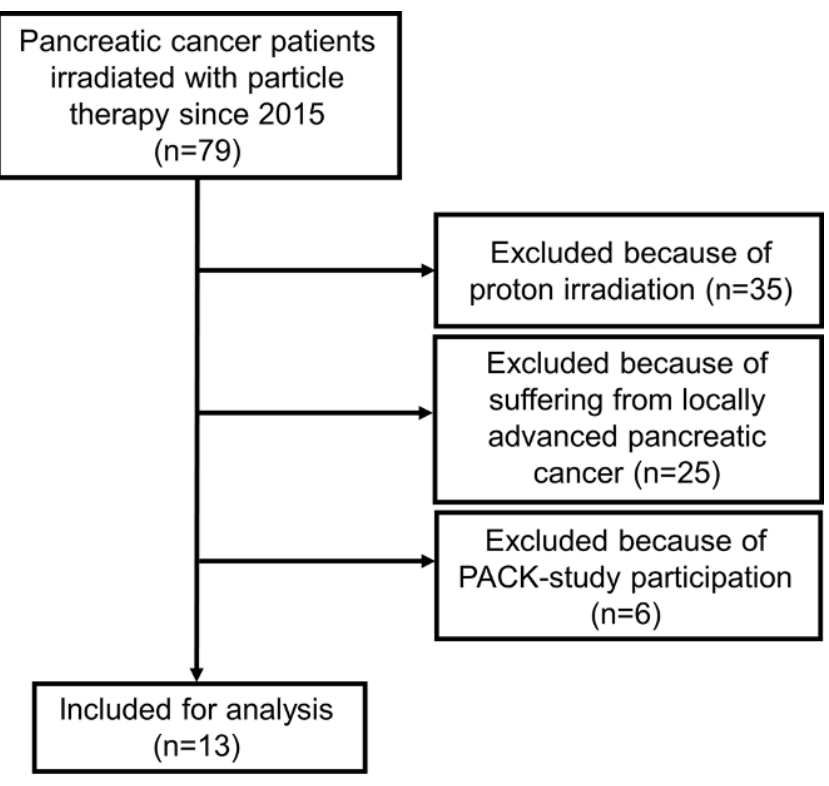

Fig. 1 Consort diagram of the patient inclusion procedure

\section{Methods}

\section{Patients}

All patients suffering from LRPC after primary resection who were irradiated with carbon ions at our institution were included in this study. Clinical information was extracted from the charts. Patients participating in the ongoing PACK trial [18] were excluded from the analysis (Fig. 1). Tumor staging needed to be done by computed tomography of the chest and the abdomen within 3 months prior to irradiation. Patients with distant metastases were not deemed suitable for carbon ion radiotherapy, although one patient presented with a pre-radiotherapy American Joint Committee on Cancer (AJCC) stage IV due to a peritoneal tumor lesion that was removed during the initial Whipple procedure.

\section{Radiotherapy}

For radiation planning, patients underwent contrast-enhanced four-dimensional computed tomography (4D-CT) with a slice thickness of $3 \mathrm{~mm}$. Radiation planning was performed using the inverse treatment planning system Syngo RT Planning (Siemens, Erlangen, Germany). Patients were irradiated in free-breathing using an internal target volume (ITV) concept and should have fasted for 3 hours prior to irradiation. The underlying biological plan optimization includes the local effect model (LEM) I, developed at the GSI Helmholtzzentrum für Schwerionenforschung and at HIT $[19,20]$. The $\alpha / \beta$ ratio for LEM I was mostly $(92 \%)$ set at $5 \mathrm{~Gy}$ for the ITV and at $2 \mathrm{~Gy}$ for the organs at risk (OARs). A total dose of $48 \mathrm{~Gy}$ (RBE) was delivered in 
12 fractions in all but one case. In the remaining case, 44 Gy (RBE) was delivered in 11 fractions. Forty-eight Gy (RBE) corresponds to an equivalent dose at $2 \mathrm{~Gy}$ (EQD2) of $61.7 \mathrm{~Gy}$ and to a BED of $86.4 \mathrm{~Gy}$, assuming an $\alpha / \beta$ ratio of 5 Gy $(\alpha / \beta=2$ Gy: EQD2=72 Gy, BED=144Gy). Treatment planning and irradiation were mostly performed in supine position (92\%) using two dorsal oblique radiation beams $(92 \%)$. One patient was irradiated in prone position and another patient received irradiation using a single radiation beam.

The following dose constraints for the OARs were given but could not always be respected: less than $20 \%$ of the kidney volume should receive more than $24 \mathrm{~Gy}(\mathrm{RBE})$; maximum dose in the spinal cord was set at $36 \mathrm{~Gy}(\mathrm{RBE})$; in the upper gastrointestinal tract, no more than 43.2 Gy (RBE) should be delivered; the liver should be irradiated as low as reasonably achievable (ALARA).

\section{Target volume definition}

The gross tumor volume (GTV) was defined as macroscopic tumor on imaging. The clinical target volume (CTV) accounting for microscopic tumor spread was individually adjusted. Two patients (15\%) presented with regional lymphatic metastases that were included in the CTV. The ITV consisted of the CTV that was adjusted for respiratory movement. An expansion of the ITV by $5 \mathrm{~mm}$ and $7 \mathrm{~mm}$ in beam direction was used to generate the planning target volume (PTV). Radiotherapy was performed with an intensity-controlled raster-scanning system for beam application at a rotating gantry.

\section{Follow-up and response evaluation}

Follow-up was defined from the first day of radiation until last clinical evaluation or death. Follow-up was performed every 3 months by contrast-enhanced CT scans and clinical evaluation, whenever this was available. Tumor response was evaluated according to the RECIST 1.1 criteria [21]. Local tumor recurrence was defined as tumor progression within the high-dose ( $>90 \%$ of the prescribed dose) radiation area. Tumor recurrences outside this area were denominated as regional tumor recurrence, if restricted to the pancreas or the operation bed with its adjacent lymphatics. Any other tumor recurrence was defined as distant tumor recurrence.

The OS was defined as time from the start of radiotherapy until reported death due to any cause. Local control (LC) was defined from the start of radiotherapy until local tumor recurrence or last imaging available. Locoregional control (LRC) was defined from the start of radiotherapy until local or regional tumor recurrence or last imaging available. Freedom from distant metastasis (FFDM) was defined from the start of radiotherapy until first occurrence of distant metastasis or last imaging available. Progressionfree survival (PFS) was defined as time from the start of radiotherapy until any tumor progression or death or last imaging available.

\section{Toxicity evaluation}

Toxicity was defined according to the International Common Terminology Criteria for Adverse Events of the National Cancer Institute (NCI CTCAE), version 5. Acute toxicity included symptoms that occurred $<3$ months after irradiation. Late toxicity was defined as symptoms that lasted for $\geq 3$ months after radiotherapy.

\section{Statistics}

OS, LC, LRC, FFDM, and PFS were analyzed using the Kaplan-Meier method. Statistics and figures were performed with SPSS Statistics, version 27 (International Business Machines Corporation: IBM, Armonk, NY, USA).

\section{Results}

\section{Patient and treatment characteristics}

Between May 2015 and February 2019, 13 LRPC patients were irradiated with carbon ions at HIT. A median total dose of $48 \mathrm{~Gy}$ (RBE) was delivered in 12 fractions using an active raster-scanning technique at a rotating gantry. No concomitant chemotherapy was administered. Patient and treatment characteristics are shown in Tables 1 and 2. A representative radiation plan is shown in Fig. 2.

\section{Follow-up}

The analysis was performed 18 months after the last patient finished radiotherapy. Median follow-up time was 9.5 months and, in the alive patient, 33.8 months. Median time interval from the start of radiotherapy until the last available imaging was 8.4 months.

\section{Overall survival}

Median OS was 12.7 months with a $95 \%$ confidence interval (CI) of 7.4-18.0 (Fig. 3a). At the time of analysis, one patient was still alive. The 1 -year and 2 -year OS rates were $58.3 \%$ and $25 \%$, respectively. Median OS after initial resection was 45.2 months (95\% CI 18.8-71.6). 
Table 1 Patient characteristics

\begin{tabular}{|c|c|c|}
\hline Number of patients & $\begin{array}{l}n \\
13\end{array}$ & $\begin{array}{l}(\%) \\
(100)\end{array}$ \\
\hline \multicolumn{3}{|l|}{$\operatorname{Sex}$} \\
\hline Male & 5 & $(38)$ \\
\hline Female & 8 & $(62)$ \\
\hline $\begin{array}{l}\text { Age at radiotherapy (median in } \\
\text { years, range) }\end{array}$ & $70(48-77)$ & - \\
\hline \multicolumn{3}{|c|}{ Localization of initial pancreatic cancer } \\
\hline Pancreatic head & 9 & $(69)$ \\
\hline Pancreatic body & 3 & $(23)$ \\
\hline Pancreatic tail & 1 & (8) \\
\hline \multicolumn{3}{|l|}{ Initial AJCC stage } \\
\hline IA & 1 & (8) \\
\hline IIA & 5 & $(38)$ \\
\hline IIB & 3 & $(23)$ \\
\hline III & 3 & $(23)$ \\
\hline IV & 1 & (8) \\
\hline \multicolumn{3}{|l|}{ Preoperative chemotherapy } \\
\hline FOLFIRINOX & 4 & $(31)$ \\
\hline None & 9 & $(69)$ \\
\hline \multicolumn{3}{|l|}{ Surgery } \\
\hline Whipple procedure & 8 & $(62)$ \\
\hline Total pancreatectomy & 3 & $(23)$ \\
\hline Distal pancreatectomy & 2 & $(15)$ \\
\hline \multicolumn{3}{|l|}{ Department of Surgery } \\
\hline Heidelberg University Hospital & 9 & $(69)$ \\
\hline Other & 4 & $(31)$ \\
\hline \multicolumn{3}{|l|}{ Resection status } \\
\hline $\mathrm{RX}$ & 1 & (8) \\
\hline $\mathrm{R} 1$ & 8 & $(62)$ \\
\hline R0 & 4 & $(30)$ \\
\hline \multicolumn{3}{|l|}{ Histology } \\
\hline Ductal adenocarcinoma & 13 & $(100)$ \\
\hline \multicolumn{3}{|l|}{ Grading } \\
\hline G1 & 1 & $(8)$ \\
\hline $\mathrm{G} 2$ & 6 & $(46)$ \\
\hline G3 & 3 & $(23)$ \\
\hline Unknown & 3 & $(23)$ \\
\hline \multicolumn{3}{|l|}{ Postoperative chemotherapy } \\
\hline FOLFIRINOX & 4 & $(31)$ \\
\hline Gemcitabine-based chemotherapy & 6 & $(46)$ \\
\hline Unknown chemotherapy & 1 & (8) \\
\hline None & 2 & $(15)$ \\
\hline
\end{tabular}

AJCC American Joint Committee on Cancer; FOLFIRINOX Chemotherapy regimen consisting of folinic acid, fluorouracil, irinotecan, and oxaliplatin

\section{Local control and locoregional control}

Local tumor recurrence was observed in one patient 6 months after carbon ion radiotherapy (Fig. $4 \mathrm{a}-\mathrm{c}$ ). This patient died 4.5 months later. The estimated 1 -year LC
Table 2 Treatment characteristics

\begin{tabular}{|c|c|c|}
\hline & $n$ & $(\%)$ \\
\hline \multicolumn{3}{|l|}{ Radiotherapy } \\
\hline $\begin{array}{l}\text { Time in months: resection to local } \\
\text { tumor recurrence (median, range) }\end{array}$ & $14(4-41)$ & - \\
\hline $\begin{array}{l}\text { Time in months: resection to radio- } \\
\text { therapy (median, range) }\end{array}$ & $19(6-51)$ & - \\
\hline \multicolumn{3}{|l|}{ Pre-radiotherapy AJCC* stage } \\
\hline III & 12 & $(92)$ \\
\hline IV & 1 & (8) \\
\hline \multicolumn{3}{|l|}{ Radiation technique } \\
\hline Carbon ions, active raster-scanning & 13 & $(100)$ \\
\hline \multicolumn{3}{|l|}{ Prescribed dose } \\
\hline $48 \mathrm{~Gy}(\mathrm{RBE})$ in 12 fractions & 12 & $(92)$ \\
\hline 44 Gy $(\mathrm{RBE})$ in 12 fractions & 1 & (8) \\
\hline \multicolumn{3}{|l|}{ Concurrent chemotherapy } \\
\hline None & 13 & $(100)$ \\
\hline \multicolumn{3}{|l|}{ Patient position } \\
\hline Supine & 12 & $(92)$ \\
\hline Prone & 1 & (8) \\
\hline \multicolumn{2}{|c|}{ Volume in ccm (median, range; mean, standard deviation) } & - \\
\hline GTV (gross tumor volume) & $\begin{array}{l}21.5(7.3-340.0) \\
46.8(101.0)\end{array}$ & \\
\hline CTV (clinical target volume) & $\begin{array}{l}66.2(25.6-569.3) \\
105.8(156.0)\end{array}$ & \\
\hline ITV (internal target volume) & $\begin{array}{l}85.4(44.8-679.6) \\
140.4(183.5)\end{array}$ & \\
\hline PTV (planning target volume) & $\begin{array}{l}165.0 \\
(91.5-1007.1) \\
238.9(263.3)\end{array}$ & \\
\hline \multicolumn{3}{|l|}{ Number of radiation beams } \\
\hline 2 & 12 & $(92)$ \\
\hline 1 & 1 & (8) \\
\hline \multicolumn{3}{|l|}{ Postradiation chemotherapy } \\
\hline FOLFIRINOX & 3 & $(23)$ \\
\hline Gemcitabine-based chemotherapy & 3 & (23) \\
\hline Unknown chemotherapy & 1 & $(8)$ \\
\hline None & 6 & $(46)$ \\
\hline
\end{tabular}

AJCC American Joint Committee on Cancer; FOLFIRINOX Chemotherapy regimen consisting of folinic acid, fluorouracil, irinotecan, and oxaliplatin

rate was $87.5 \%$ (Fig. 3b). Another two patients presented with regional tumor recurrences outside of the high-dose radiation area. These regional tumor recurrences occurred 7 months and 3.5 years after carbon ion radiotherapy. The corresponding estimated 1-year locoregional control was $75 \%$. One representative regional tumor recurrence is shown in Fig. $4 \mathrm{~d}-\mathrm{f}$ and $4 \mathrm{~g}-\mathrm{i}$. 
Fig. 2 Radiation plan of a 59year-old patient suffering from locally recurrent pancreatic cancer demonstrating a steep dose gradient of the performed irradiation. The patient was irradiated in supine position using two oblique posterior beams to avoid gastrointestinal toxicity. Axial (a), coronal (b), and sagittal (c) computed tomography (CT) slices and isodose lines are shown. The gross tumor volume (GTV) is delineated in green, the gastrointestinal tract is contoured in light blue. Isodoses represent a forward-calculation using an $\alpha / \beta$ ratio of $2 \mathrm{~Gy}$ in the local effect model (LEM) I. Therefore, the GTV seems to be overdosed. In the actually irradiated plan, an $\alpha / \beta$ ratio of 5 Gy in LEM I was used for the tumor tissue. d Dose-volume histogram of the radiation plan demonstrating adequate coverage of the GTV (green) while avoiding overdosage in the gastrointestinal tract (light blue)
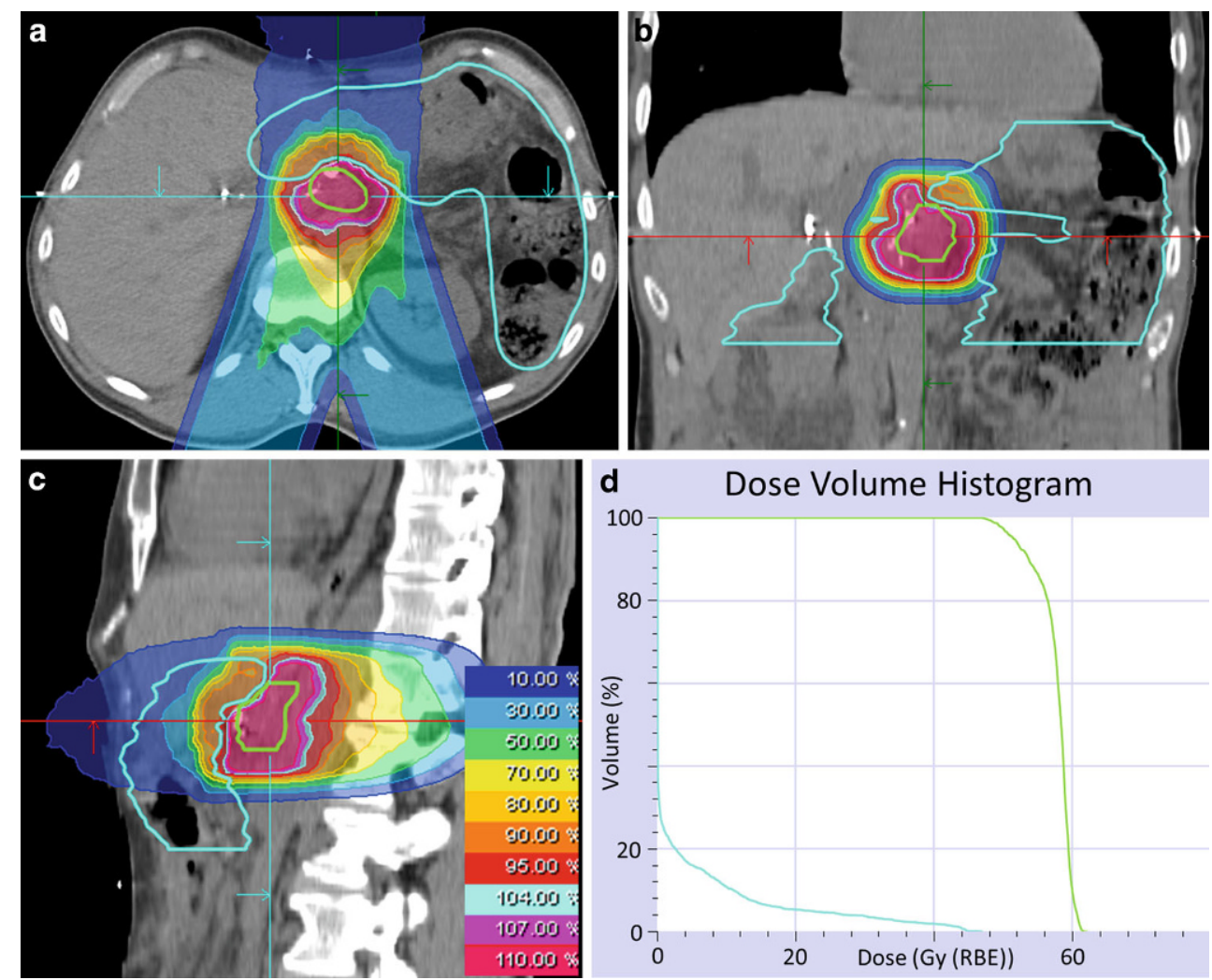

\section{Freedom from distant metastasis and progression- free survival}

Distant metastasis developed in 10 patients. The median time interval between radiotherapy and occurrence of distant metastasis was 5.4 months (95\% CI 2.9-7.9). After 6 and 12 months, an estimated $66.0 \%$ and $88.3 \%$ of the patients presented with distant tumor recurrence, respectively (Fig. 3c). With a median PFS of 5.4 months (95\% CI 3.1-7.7), an estimated $8 \%$ of the patients were free of any tumor progression after 1 year (Fig. 3d).

\section{Toxicity}

One patient developed a gastric hemorrhage CTCAE grade III during radiotherapy. This patient initially presented with a large LRPC with regional lymph node metastases. Therefore, the corresponding PTV was the largest of the cohort (1007 ccm, Table 2). The patient presented with bloody stools after having been irradiated with a total dose of $36 \mathrm{~Gy}$ (RBE). The maximum radiation dose (Dmax) in the stomach was at 35.6Gy (RBE) at that timepoint, the Dmax in the small intestine was at $39.4 \mathrm{~Gy}$ (RBE). The patient required transfusion and was temporarily monitored in the intensive care unit of our institution $(<24 \mathrm{~h})$. Endoscopic examination did not reveal the exact source of the bleeding, but radiotherapy-induced gastritis was assumed to be the reason for the hemorrhage. The patient recovered fast with conservative therapy. After a break of three radiation fractions, he resumed and completed radiotherapy without any further bleeding. Nevertheless, the radiation plan was modified, and it was decided to reduce the total dose to 44Gy (RBE) to lower the risk of gastrointestinal toxicity. During follow-up there was no further suspicion of gastrointestinal ulcer. Toxicity rates are shown in Table 3.

\section{Discussion}

In the present study, we analyzed carbon ion radiotherapy in locally recurrent pancreatic cancer for the first time in Europe. Furthermore, the abovementioned retrospective study of Kawashiro et al. provides the only published data concerning carbon ion radiotherapy in LRPC worldwide [17]. In our study, we could demonstrate encouraging local tumor control rates with a 1 -year LC rate of $87.5 \%$. This finding could be biased by the observed low OS, since patients might not have reached the endpoint of local tumor recurrence. Nevertheless, the observed LC is consistent with the hypothesis of improved efficacy when irradiating with higher RBE and BED. Furthermore, the results are comparable to local control rates with carbon ion radiotherapy in unresectable locally advanced pancreatic cancer published by Shinoto et al. [22]. 

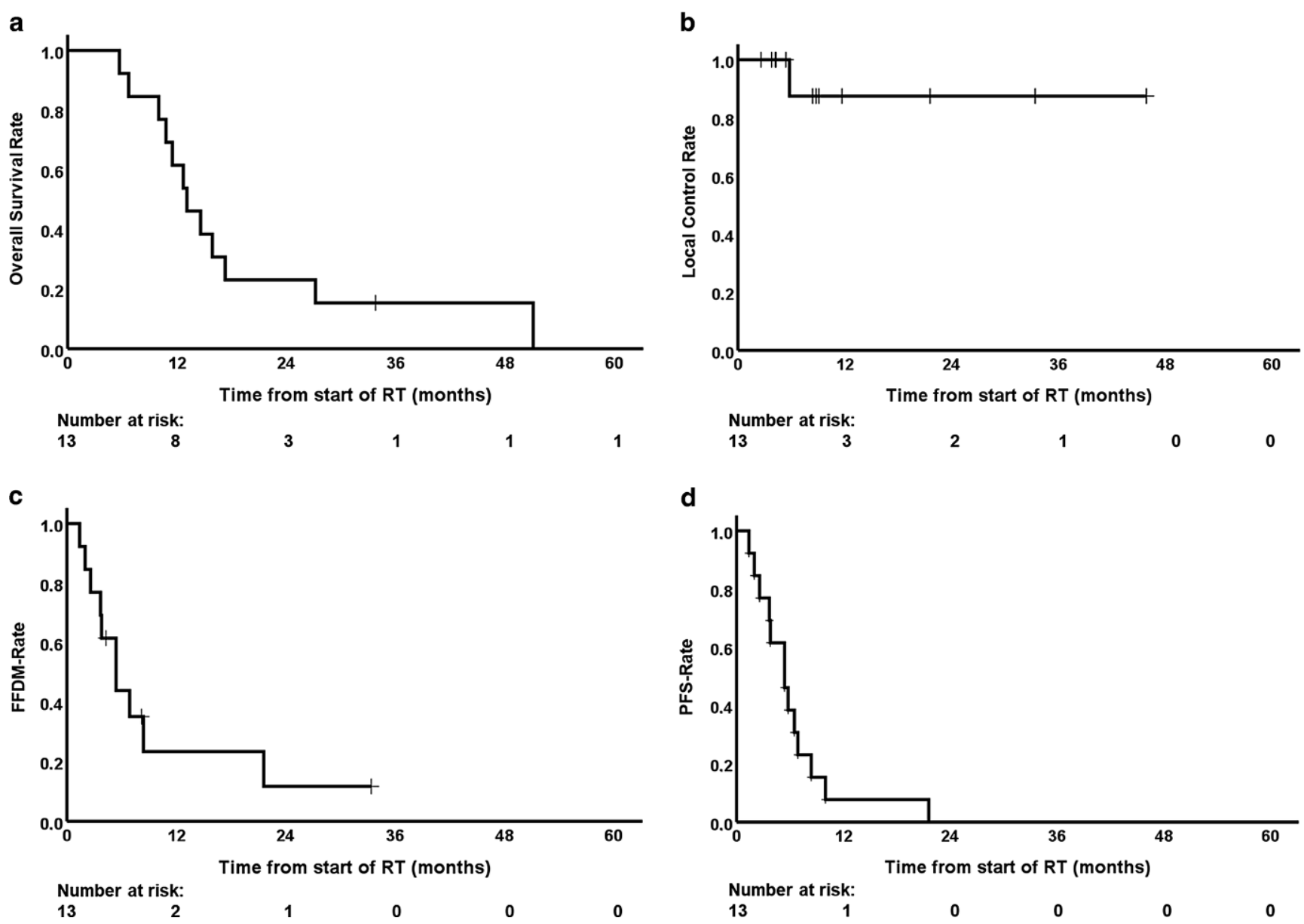

Fig. 3 Based on Kaplan-Meier estimates, a overall survival (OS), b local control (LC), $\mathbf{c}$ freedom from distant metastasis (FFDM), and d progression-free survival $(P F S)$ of 13 patients. All patients were suffering from locally recurrent pancreatic cancer (LRPC) and underwent carbon ion radiotherapy $(R T)$ at the Heidelberg Ion-Beam Therapy Center (HIT)

We observed high-grade toxicity in only one patient, in line with the low toxicity rates published by Kawashiro et al. Taking account of the fact that the patient who developed grade III gastric hemorrhage had presented with the largest tumor volume of the cohort, one could state that, at least for limited tumor volumes, the dose schedule used is safe and feasible.

Compared to historical data of photon radiotherapy in LRPC, the observed median OS was not improved. In an in-house study with 41 patients, Habermehl et al. reported a median overall survival of 16.1 months after photon radiotherapy with a median total dose of $48.4 \mathrm{~Gy}$ in 28 fractions, mostly $(90 \%)$ combined with chemotherapy with gemcitabine $300 \mathrm{mg} / \mathrm{m}^{2}$ body surface [10]. Nakamura et al. observed similar results irradiating with photons to a median total dose of $54 \mathrm{~Gy}$ in 30 fractions, predominantly (60\%) combined with chemotherapy [11]. In the present study, the median OS of 12.7 months seems lower than photon-based results. There is also a discrepancy between our findings and the observed median OS of 25.9 months after carbon ion radiotherapy in LRPC described by Kawashiro et al. [17] The following could explain these differences.

First, the underlying patient cohorts differed widely. Compared to the present study, the investigated patients were younger in the analysis of Kawashiro et al. (70 years vs. 61 years). Also, men were underrepresented in our study (38\%). Only $57 \%$ of the patients of Kawashiro et al. suffered from pancreatic head cancer. In our cohort, this subgroup was higher (69\%). Irradiating tumors in the area of the pancreatic head, gastrointestinal toxicity risk is elevated due to the proximity to the duodenum. Consequently, the radiation dose must be restricted to lower dose concepts to avoid toxicity. Also, the rate of margin-free (R0) tumor resections was much higher in Kawashiro et al.'s patient cohort (70\% compared to $30 \%$ in the presented study). This is significant, as R0 resection correlates strongly with improved survival rates in pancreatic cancer [23, 24]. Furthermore, the median PTV of the study of Kawashiro et al. was slightly smaller than the one presented in the current analysis $(162.6 \mathrm{ccm}$, range: $47.3-347.8 \mathrm{ccm}$ vs. 

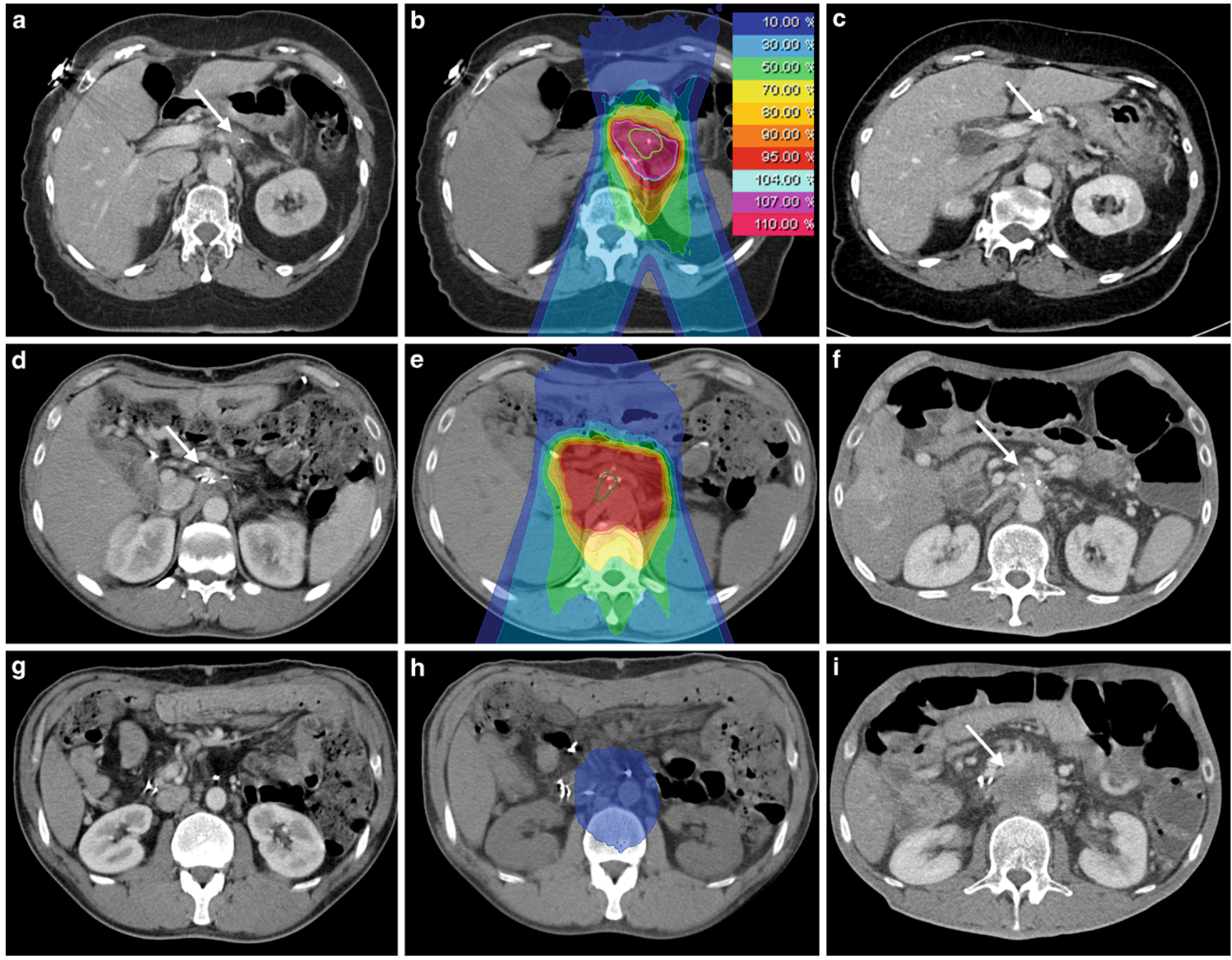

Fig. 4 a-c Baseline imaging (a), radiation plan (b), and follow-up imaging (c) of a locally recurrent pancreatic cancer (LRPC) patient showing local tumor recurrence (white arrows) after carbon ion radiotherapy. d-f Baseline imaging (d), radiation plan (e), and follow-up imaging (f) of another LRPC patient showing stable local disease (white arrows) after radiotherapy. $\mathbf{g}-\mathbf{i}$ Corresponding images of the same patient as in $\mathbf{d}-\mathbf{f}$ at a more distal location, showing regional tumor recurrence (white arrow) in follow-up imaging (i). The tumor recurrence occurred in the low-dose area (10\% isodose line) of the performed radiation $(\mathbf{h})$ and was therefore defined as regional tumor recurrence

$165.0 \mathrm{ccm}$; range: $91.5-1007.1 \mathrm{ccm})$. Altogether, the analysis of Kawashiro et al. seems to be based on healthier patients with lower tumor burden compared to the present study.

Secondly, the treatment regimen was different. Kawashiro et al. irradiated with a total dose of 52.8-55.2Gy (RBE) in 12 fractions. This dose concept seems higher than the one in the present series, i.e., $48 \mathrm{~Gy}$ (RBE) in 12 fractions. However, heavy ion doses cannot be compared nominally, as different RBE calculation models and different beam applications are used in Japan and at HIT [25]. In our study, we decided not to irradiate with doses higher than $48 \mathrm{~Gy}$ (RBE) to avoid gastrointestinal toxicity. The observed CTCAE grade III toxicity suggests that this LEM I-based dose schedule is near the maximum tolerable irradiation dose in our facility.
Most of the patients of the study of Kawashiro et al. were treated with concomitant chemotherapy, whereas patients in the present cohort did not receive concurrent chemotherapy. There are higher rates of distant tumor progression in the present study compared to the patient cohort of Kawashiro et al. (77\% vs. $63 \%$ ), and distant progression occurred early. Therefore, combining carbon ion radiotherapy with chemotherapy could be important for improving oncological outcome.

The patient cohort of 13 patients is too small to draw definitive conclusions. Nevertheless, it is worth describing this rare patient cohort for which few data on management exist. We believe that some of the lessons gleaned from this experience can be applied to other settings in which carbon ion radiotherapy is used in the abdomen. Given the limited number of carbon ion radiotherapy facilities worldwide, 
Table 3 Toxicity rates

\begin{tabular}{|c|c|c|c|}
\hline $\begin{array}{l}\text { Symptoms } \\
\text { (NCI CTCAE } \\
\text { grades) }\end{array}$ & $\begin{array}{l}\text { Before RT } \\
n(\%)\end{array}$ & $\begin{array}{l}\text { Acute toxicity } \\
n(\%)\end{array}$ & $\begin{array}{l}\text { Late toxicity } \\
n(\%)\end{array}$ \\
\hline \multicolumn{4}{|l|}{ Abdominal pain } \\
\hline I & $4(31)$ & $1(8)$ & $3(23)$ \\
\hline II & 1 & $3(23)$ & $1(8)$ \\
\hline \multicolumn{4}{|c|}{ Gastric hemorrhage } \\
\hline III & 0 & $1(8)$ & 0 \\
\hline \multicolumn{4}{|l|}{ Gastritis } \\
\hline II & 0 & $1(8)$ & 0 \\
\hline \multicolumn{4}{|l|}{ Diarrhea } \\
\hline I & $4(31)$ & $3(23)$ & $1(8)$ \\
\hline II & $1(8)$ & 0 & 0 \\
\hline \multicolumn{4}{|l|}{ Ascites } \\
\hline I & $1(8)$ & $1(8)$ & $1(8)$ \\
\hline II & 0 & $1(8)$ & 0 \\
\hline \multicolumn{4}{|l|}{ Nausea } \\
\hline I & $5(38)$ & $3(23)$ & $1(8)$ \\
\hline II & 0 & $2(15)$ & 0 \\
\hline \multicolumn{4}{|l|}{ Dermatitis } \\
\hline I & 0 & $1(8)$ & 0 \\
\hline \multicolumn{4}{|l|}{ Fatigue } \\
\hline I & $2(15)$ & $2(15)$ & $2(15)$ \\
\hline II & 0 & $2(15)$ & 0 \\
\hline No complaints & $3(23)$ & $5(38)$ & $3(23)$ \\
\hline
\end{tabular}

$R T$ radiotherapy, NCI CTCAE Common Terminology Criteria for Adverse Events of the National Cancer Institute

very few reports on clinical outcomes have been published. There is growing interest in particle radiotherapy in pancreatic cancer, since promising results have recently been reported in Japan [17, 22, 26-28]. Currently, the ongoing phase II PACK trial is prospectively investigating carbon ion radiotherapy in non-metastasized pancreatic cancer and will deepen knowledge in this promising field of research [18].

\section{Conclusion}

In the present study, we could demonstrate excellent local tumor control rates and low toxicity rates after carbon ion radiotherapy in LRPC. However, we could not confirm improvement of OS rates. Based on our findings, systemic treatment should be considered concomitantly and after carbon ion radiotherapy of locally recurrent pancreatic cancer patients due to the observed high rate of distant metastases.

Funding Jakob Liermann is funded by the Physician-Scientist Program of Heidelberg University, Faculty of Medicine.

Author Contribution JL, EBJ, and PN designed the study. JL analyzed and interpreted the patient data. JL, EBJ, MS, JD, KH, and PN con- tributed to the manuscript. All authors contributed to and approved the final version of the manuscript.

Funding Open Access funding enabled and organized by Projekt DEAL.

\section{Declarations}

Conflict of interest J. Debus received grants from Viewray Incorporated, The Clinical Research Institute GmbH (CRI), Accuray International Sarl, RaySearch Laboratories AB, Vision RT Limited, Merck Seono GmbH, Astellas Pharma GmbH, Astra Zeneca GmbH, Siemens Healthcare GmbH, Solution Akademie GmbH, Egomed PLC Surrey Research Park, Quintiles GmbH, Pharmaceutical Research Associates $\mathrm{GmbH}$, Boehringer Ingelheim Pharma GmbH\&CoKG, PTW-Freiburg Dr. Pychlau GmbH, Nanobiotix SA, Accuray Incorporated, BristolMyer Squibb GmbH\&CoKG aA, and Merck KHG aA. As chairman of HIRO (Heidelberg Institute of Radiation Oncology, Heidelberg, Germany) and a managing director of the NCT (National Center for Tumor Diseases) Heidelberg, Germany, J. Debus is responsible for collaborations with a multitude of companies and institutions. Juergen Debus is $\mathrm{CEO}$ of the HIT Betriebs-GmbH and a member of the board of trustees of the Physikalisch-Technische Bundesanstalt (PTB). He attended advisory board meetings of MERCK KGaA (Darmstadt). J. Liermann, E. Ben-Josef, M. Syed, K. Herfarth, and P. Naumann declare that they have no competing interests.

Ethical standards The presented study is in accordance with the ethical standards of the institutional research committee (ethics committee of the University of Heidelberg, Germany, S-688/2020) and with the 1975 Helsinki declaration and its later amendments or comparable ethical standards.

Open Access This article is licensed under a Creative Commons Attribution 4.0 International License, which permits use, sharing, adaptation, distribution and reproduction in any medium or format, as long as you give appropriate credit to the original author(s) and the source, provide a link to the Creative Commons licence, and indicate if changes were made. The images or other third party material in this article are included in the article's Creative Commons licence, unless indicated otherwise in a credit line to the material. If material is not included in the article's Creative Commons licence and your intended use is not permitted by statutory regulation or exceeds the permitted use, you will need to obtain permission directly from the copyright holder. To view a copy of this licence, visit http://creativecommons.org/licenses/by/4. $0 /$.

\section{References}

1. Rawla P, Sunkara T, Gaduputi V (2019) Epidemiology of pancreatic cancer: global trends, etiology and risk factors. World J Oncol 10(1):10-27. https://doi.org/10.14740/wjon1166

2. Fietkau R, Grutzmann R, Wittel UA, Croner RS, Jacobasch L, Neumann UP, Reinacher-Schick A, Imhoff D, Boeck S, Keilholz L, Oettle H, Hohenberger WM, Golcher H, Bechstein WO, Uhl W, Pirkl A, Adler W, Semrau S, Rutzner S, Ghadimi M, Lubgan D (2021) R0 resection following chemo (radio)therapy improves survival of primary inoperable pancreatic cancer patients. Interim results of the German randomized CONKO-007+/- trial. Strahlenther Onkol 197(1):8-18. https://doi.org/10.1007/s00066-020-01680-2

3. Oettle H, Post S, Neuhaus P, Gellert K, Langrehr J, Ridwelski K, Schramm H, Fahlke J, Zuelke C, Burkart C, Gutberlet K, Kettner E, Schmalenberg H, Weigang-Koehler K, Bechstein WO, Niedergethmann M, Schmidt-Wolf I, Roll L, Doerken B, Riess H (2007) Adjuvant chemotherapy with gemcitabine vs observation in patients 
undergoing curative-intent resection of pancreatic cancer: a randomized controlled trial. JAMA 297(3):267-277. https://doi.org/ 10.1001/jama.297.3.267

4. Ferrone CR, Brennan MF, Gonen M, Coit DG, Fong Y, Chung S, Tang L, Klimstra D, Allen PJ (2008) Pancreatic adenocarcinoma: the actual 5-year survivors. J Gastrointest Surg 12(4):701-706. https://doi.org/10.1007/s11605-007-0384-8

5. Groot VP, Rezaee N, Wu W, Cameron JL, Fishman EK, Hruban RH, Weiss MJ, Zheng L, Wolfgang CL, He J (2018) Patterns, timing, and predictors of recurrence following pancreatectomy for pancreatic ductal adenocarcinoma. Ann Surg 267(5):936-945. https://doi. org/10.1097/SLA.0000000000002234

6. Iacobuzio-Donahue CA, Fu B, Yachida S, Luo M, Abe H, Henderson CM, Vilardell F, Wang Z, Keller JW, Banerjee P, Herman JM, Cameron JL, Yeo CJ, Halushka MK, Eshleman JR, Raben M, Klein AP, Hruban RH, Hidalgo M, Laheru D (2009) DPC4 gene status of the primary carcinoma correlates with patterns of failure in patients with pancreatic cancer. J Clin Oncol 27(11):1806-1813. https://doi.org/10.1200/JCO.2008.17.7188

7. Strobel O, Hartwig W, Hackert T, Hinz U, Berens V, Grenacher L, Bergmann F, Debus J, Jager D, Buchler M, Werner J (2013) Reresection for isolated local recurrence of pancreatic cancer is feasible, safe, and associated with encouraging survival. Ann Surg Oncol 20(3):964-972. https://doi.org/10.1245/s10434-012-2762-z

8. Miyazaki M, Yoshitomi H, Shimizu H, Ohtsuka M, Yoshidome H, Furukawa K, Takayasiki T, Kuboki S, Okamura D, Suzuki D, Nakajima M (2014) Repeat pancreatectomy for pancreatic ductal cancer recurrence in the remnant pancreas after initial pancreatectomy: is it worthwhile? Surgery 155(1):58-66. https://doi.org/10.1016/j.surg. 2013.06.050

9. Zhou Y, Song A, Wu L, Si X, Li Y (2016) Second pancreatectomy for recurrent pancreatic ductal adenocarcinoma in the remnant pancreas: a pooled analysis. Pancreatology 16(6):1124-1128. https:// doi.org/10.1016/j.pan.2016.09.015

10. Habermehl D, Brecht IC, Bergmann F, Welzel T, Rieken S, Werner J, Schirmacher P, Buchler MW, Debus J, Combs SE (2013) Chemoradiation in patients with isolated recurrent pancreatic cancer-Therapeutical efficacy and probability of re-resection. Radiat Oncol 8:27. https://doi.org/10.1186/1748-717X-8-27

11. Nakamura A, Itasaka S, Takaori K, Kawaguchi Y, Shibuya K, Yoshimura M, Matsuo Y, Mizowaki T, Uemoto S, Hiraoka M (2014) Radiotherapy for patients with isolated local recurrence of primary resected pancreatic cancer. Prolonged disease-free interval associated with favorable prognosis. Strahlenther Onkol 190(5):485-490. https://doi.org/10.1007/s00066-014-0610-8

12. Comito T, Cozzi L, Zerbi A, Franzese C, Clerici E, Tozzi A, Iftode C, Navarria P, D'Agostino G, Fogliata A, Mancosu P, Tomatis S, Carnaghi C, Personeni N, Santoro A, Scorsetti M (2017) Clinical results of stereotactic body radiotherapy (SBRT) in the treatment of isolated local recurrence of pancreatic cancer after R0 surgery: a retrospective study. Eur J Surg Oncol 43(4):735-742. https://doi.org/10.1016/j.ejso.2016.12.012

13. Ryan JF, Groot VP, Rosati LM, Hacker-Prietz A, Narang AK, McNutt TR, Jackson JF, Le DT, Jaffee EM, Zheng L, Laheru DA, He J, Pawlik TM, Weiss MJ, Wolfgang CL, Herman JM (2018) Stereotactic body radiation therapy for isolated local recurrence after surgical resection of pancreatic ductal adenocarcinoma appears to be safe and effective. Ann Surg Oncol 25(1):280-289. https://doi.org/ 10.1245/s10434-017-6134-6

14. Zimmermann C, Distler M, Jentsch C, Blum S, Folprecht G, Zophel K, Polster H, Troost EGC, Abolmaali N, Weitz J, Baumann M, Saeger HD, Grutzmann R (2021) Evaluation of response using FDG-PET/CT and diffusion weighted MRI after radiochemotherapy of pancreatic cancer: a non-randomized, monocentric phase II clinical trial-PaCa-DD-041 (Eudra-CT 2009-
011968-11). Strahlenther Onkol 197(1):19-26. https://doi.org/10. 1007/s00066-020-01654-4

15. Liermann J, Shinoto M, Syed M, Debus J, Herfarth K, Naumann P (2020) Carbon ion radiotherapy in pancreatic cancer: a review of clinical data. Radiother Oncol 147:145-150. https://doi.org/10. 1016/j.radonc.2020.05.012

16. Mizumoto T, Terashima K, Matsuo Y, Nagano F, Demizu Y, Mima M, Sulaiman NS, Tokumaru S, Okimoto T, Toyama H, Fukumoto T (2019) Proton radiotherapy for isolated local recurrence of primary resected pancreatic ductal adenocarcinoma. Ann Surg Oncol 26(8):2587-2594. https://doi.org/10.1245/s10434-01907471-z

17. Kawashiro S, Yamada S, Isozaki Y, Nemoto K, Tsuji H, Kamada $\mathrm{T}$ (2018) Carbon-ion radiotherapy for locoregional recurrence after primary surgery for pancreatic cancer. Radiother Oncol 129(1):101-104. https://doi.org/10.1016/j.radonc.2018.02.003

18. Liermann J, Naumann P, Hommertgen A, Pohl M, Kieser M, Debus J, Herfarth K (2020) Carbon ion radiotherapy as definitive treatment in non-metastasized pancreatic cancer: study protocol of the prospective phase II PACK-study. BMC Cancer 20(1):947. https:// doi.org/10.1186/s12885-020-07434-8

19. Weyrather WK, Kraft G (2004) RBE of carbon ions: experimental data and the strategy of RBE calculation for treatment planning. Radiother Oncol 73(Suppl 2):S161-S169. https://doi.org/10.1016/ s0167-8140(04)80041-0

20. Kramer M, Scholz M (2000) Treatment planning for heavy-ion radiotherapy: calculation and optimization of biologically effective dose. Phys Med Biol 45(11):3319-3330. https://doi.org/10.1088/ 0031-9155/45/11/314

21. Eisenhauer EA, Therasse P, Bogaerts J, Schwartz LH, Sargent D, Ford R, Dancey J, Arbuck S, Gwyther S, Mooney M, Rubinstein L, Shankar L, Dodd L, Kaplan R, Lacombe D, Verweij J (2009) New response evaluation criteria in solid tumours: revised RECIST guideline (version 1.1). Eur J Cancer 45(2):228-247. https://doi. org/10.1016/j.ejca.2008.10.026

22. Shinoto M, Yamada S, Terashima K, Yasuda S, Shioyama Y, Honda H, Kamada T, Tsujii H, Saisho H (2016) Carbon ion radiation therapy with concurrent gemcitabine for patients with locally advanced pancreatic cancer. Int J Radiat Oncol Biol Phys 95(1):498-504. https://doi.org/10.1016/j.ijrobp.2015.12.362

23. Tummers WS, Groen JV, Sibinga Mulder BG, Farina-Sarasqueta A, Morreau J, Putter H, van de Velde CJ, Vahrmeijer AL, Bonsing BA, Mieog JS, Swijnenburg RJ (2019) Impact of resection margin status on recurrence and survival in pancreatic cancer surgery. Br J Surg 106(8):1055-1065. https://doi.org/10.1002/bjs.11115

24. Tummala P, Howard T, Agarwal B (2013) Dramatic survival benefit related to R0 resection of pancreatic adenocarcinoma in patients with tumor $\leq 25 \mathrm{~mm}$ in size and $\leq 1$ involved lymph nodes. Clin Transl Gastroenterol 4:e33. https://doi.org/10.1038/ctg.2013.4

25. Steinstrater O, Grun R, Scholz U, Friedrich T, Durante M, Scholz M (2012) Mapping of RBE-weighted doses between HIMAC- and LEM-Based treatment planning systems for carbon ion therapy. Int J Radiat Oncol Biol Phys 84(3):854-860. https://doi.org/10.1016/j. ijrobp.2012.01.038

26. Shinoto M, Terashima K, Suefuji H, Matsunobu A, Toyama S, Fukunishi K, Shioyama Y (2018) A single institutional experience of combined carbon-ion radiotherapy and chemotherapy for unresectable locally advanced pancreatic cancer. Radiother Oncol 129(2):333-339. https://doi.org/10.1016/j.radonc.2018.08.026

27. Kawashiro S, Yamada S, Okamoto M, Ohno T, Nakano T, Shinoto M, Shioyama Y, Nemoto K, Isozaki Y, Tsuji H, Kamada T (2018) Multi-institutional study of carbon-ion radiotherapy for locally advanced pancreatic cancer: Japan Carbon-ion Radiation Oncology Study Group (J-CROS) study 1403 pancreas. Int J Radiat Oncol Biol Phys 101(5):1212-1221. https://doi.org/10.1016/j.ijrobp. 2018.04.057 
28. Shinoto M, Yamada S, Yasuda S, Imada H, Shioyama Y, Honda H, Kamada T, Tsujii H, Saisho H (2013) Phase 1 trial of preoperative, short-course carbon-ion radiotherapy for patients with resectable pancreatic cancer. Cancer 119(1):45-51. https://doi.org/10.1002/ cncr. 27723 